Vol 4, No 1 (2021): Stadium - Hungarian Journal of Sport Sciences

https://doi.org/10.36439/shjs/2021/1/9450

\title{
PSYCHOLOGICAL STRESS MONITORING USING INVASIVE AND NON- INVASIVE METHODS IN ATHLETES
}

\author{
Gabriella Makra, László Balogh \\ Institute of Sport Sciences University of Debrecen, Debrecen, Hungary
}

\begin{abstract}
Introduction: The quality of performance is essential both in everyday life and in competition. In sports science (also), we have to think of the man in a complex way as a bio-psycho-social unit. In addition to changes in ECG HR and blood cortisol levels, gastrointestinal tract movements are also associated with stress management (FUKUNAGA et al., 2000) (VIANNA - TRANEL, 2006), which plays a crucial role in determining the quality of performance. Several preclinical trials have formed the basis of our research (SZÜCS et al., 2018).

Objective: Based on our earlier research and literature reviews, we would like to test and participate in validating a new method that can monitor the effects of stress on humans in real-time, in a noninvasive way, with quantitative results. In addition to GI monitoring, cortisol levels are measured invasively in the subjects, so we hope to obtain complex results.
\end{abstract}

Methods: $n=13$, athletes, male $=11$, female $=2$, mean age $22+/-1,031$ years. Our protocol was 115 minutes, in which we distinguished four stages (rest, stress, latency 1, latency 2). We use two methods to measure stress. One is the blood cortisol level (ELISA), and the other is the MDE Heidelberg Stress Holter (EGG), which is an innovative measurement tool capable of simultaneously examining several parameters (Small Intestine, Colon, Stomach, ECG HR). The VTS DT package was used as a stressor.

Result: Based on the complex results of the EGG, we can conclude that the Small Intestine, Colon, and Stomach motility, as assessed by the Power Spectrum (PS) Fold Change (FC) calculation, increased together under stress, and then latency decreased together over time. However, the rate of change in cortisol levels showed that most participants adapted the stressor as eustress so that its value decreased linearly.

Conclusions: Innovative measurement and evaluation methods are well utilized, as they can communicate many measurement data in a valid, real-time, non-invasive way, with a parallel display. These data and results will be used in athlete selection, mental training, elite sports, neurobiofeedback, and health preservation.

Keywords: psychological stress, stress holter, eustress, distress, gastrointestinal motility, performance 


\section{INTRODUCTION}

A healthy lifestyle has become a very fashionable topic nowadays, one of the cornerstones of sports.

"Sport: According to the European Sports Charter (1992)," any physical activity which, occasionally or in an organized form, serves to improve physical and mental fitness, to establish social connections or to achieve results in competitions at different levels. " Sport presupposes and develops appropriate psychomotor skills. It is regulated, purposeful, usually - but not always - based on competition and struggle. Many times it requires determination, risk-taking; other times, it requires manual dexterity and playfulness. Sport is an outstanding field of physical culture, which affects the whole personality, the intellectual, social, social, moral, emotional-will characteristics, and abilities of man as a bio-psycho-social unit."(BALOGH, 2015 based on RÉTSÁGI, 2011)

As a key idea, I would like to highlight the following part: "man as a bio-psycho-social unit."

"Man is defined from three sides: biological, psychic, and social being. ... Man like ...

Biological being: Feeds, rests, produces the necessities of life, takes care of offspring;

Psychological being: It has an emotional, intellectual, volitional function;

Social being: Characterized by being small and large communities (family, school, workplace, etc.). "1

It is, therefore, essential to investigate this topic in a complex way. Therefore, sports science has a great responsibility. As a multidisciplinary discipline, it can produce detailed measurements and results that can impact all areas of life by combining many other fields. It is, therefore, necessary to develop and incorporate innovative processes that can keep pace with this approach. These play a vital role in developing performance diagnostics, as measuring instruments with real-time, quantitative results that can be used in direct practice can significantly reduce the effects of subjective factors.

A person can perform well, relative to himself (depends on individual conditioning state, coordination, emotional, and cognitive abilities) only well or better (because development is the goal) if all parameters work at an appropriate, or at least satisfactory, level. As soon as one or even more of these parameters tip over simultaneously, the harmony disappears, and the whole wonderfully created methodology is overturned. As I

\footnotetext{
${ }^{1}$ http://centroszet.hu/tananyag/egeszsegtudatos/122_az_ember_mint_bioszocilis_Iny.html
} 
mentioned earlier, it is crucial to evaluate everyone individually, as each person is different, so this is the only way we can get individualized, realistic values.

The topic of our previous literature review (MAKRA - BALOGH, 2018) was to examine the relationship between physical activity and cognitive abilities. Cognitive abilities are defined as follows: "Cognitive processes and abilities realize intellectual functioning, which can be divided into two large groups, direct (perception, observation, attention) and indirect (memory, imagination, thinking) cognitive processes."2

"... Fifty articles, nearly 150 research were reviewed.

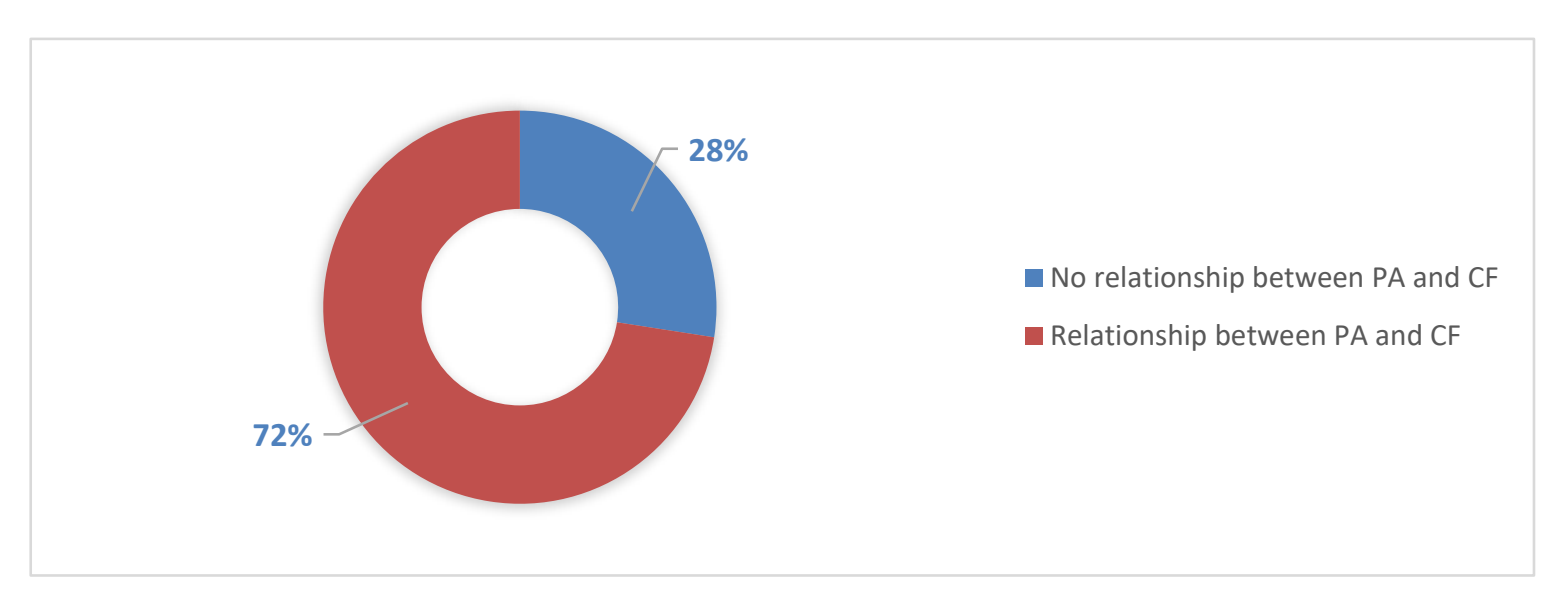

Figure 1: Total measurement results

Source: own figure

$72 \%$ of the research shows a specific relationship between the two aspects examined (physical activity and cognitive function). This is a two-way interaction. (MAKRA BALOGH, 2018)

Physical activity and sport have a significant effect on motor skills and cognitive functions, including the psyche.

One of today's most popular topics is stress, which is often used with inappropriate meaning. Stress research dates back to the late 19th century, under French scientist Claude Bernard, who defined the internal environment and equilibrium concepts. This concept became known as milieu interieur and then as homeostasis. "The stability of the internal environment is the primary condition for the freedom and independence of existence." (BERNARD, 19th CENTURY). The concept was later clarified. "The ability of a living organism to adapt to changing external and internal conditions, thereby ensuring its relative biological stability." (CANNON, 1926) The specific definition of stress is linked to the name of János Selye: "The body's non-specific reaction to any stimulus that ticks it 
out of its original state of equilibrium and causes it to adapt." (SELYE, 1936) He defined the stress-inducing stimulus as a stressor. János Selye also dealt with and described the effects of stress, a general adaptation syndrome (GAS), which shows the course and stages of the stressor-induced reaction (see Figure 1).

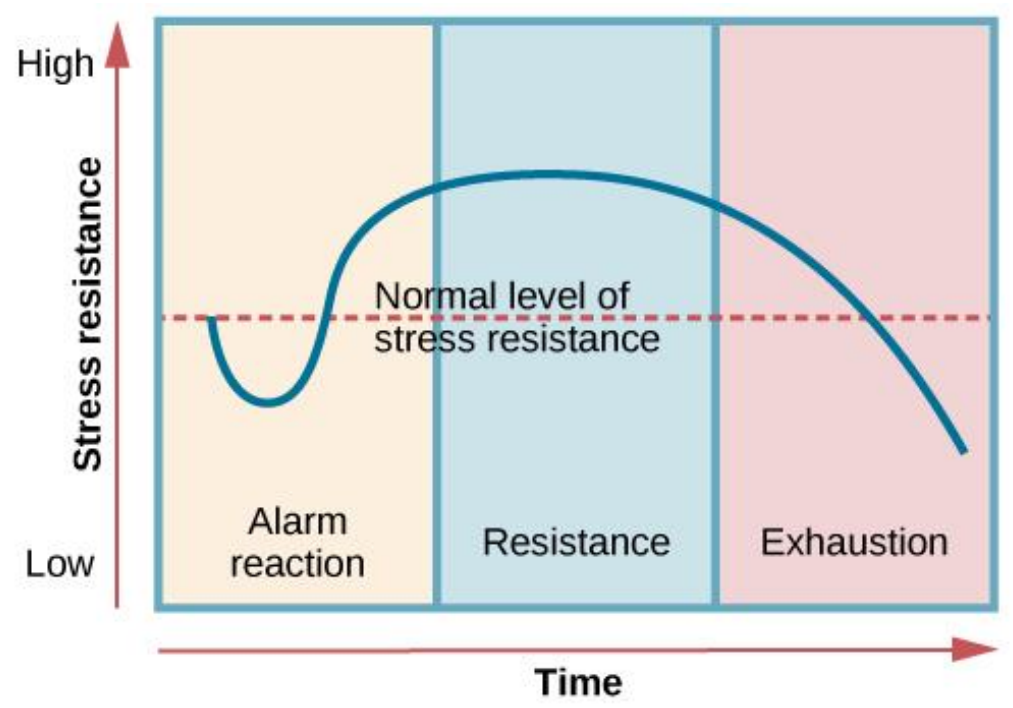

Figure 1: Three phases of Selye's general adaptation syndrome (GAS)

Sources: https://courses.lumenlearning.com/waymaker-psychology/chapter/studyingstress/

This process can be divided into three main phases. The first is the alarm reaction that occurs immediately after the stressor appears. The organization must decide what to do (flee or struggle). This phase is also known as "fight or flight"; it is "hit or run in Hungarian." This is when the body's reserve energies are activated (increased sympathetic nervous system), thus preparing for adaptation. During the active resistance phase, the body releases additional reserves for the most effective resistance possible. However, it cannot make up for this, so if the stress situation persists for a long time, the body will be exhausted. This is when stress-induced illnesses occur, which may cause death.

For this reason, we can state that, according to Selye's definition, movement, which is physical stress, can also be called stress. Still, stress can also be called solving a theoretical problem, which is psychological stress. Stress is not a negative thing, but the stress response we generate can negatively affect our bodies and performance. The regularity recognized by Yerkes-Dodson is well illustrated in Figure 2. 
Vol 4, No 1 (2021): Stadium - Hungarian Journal of Sport Sciences https://doi.org/10.36439/shjs/2021/1/9450

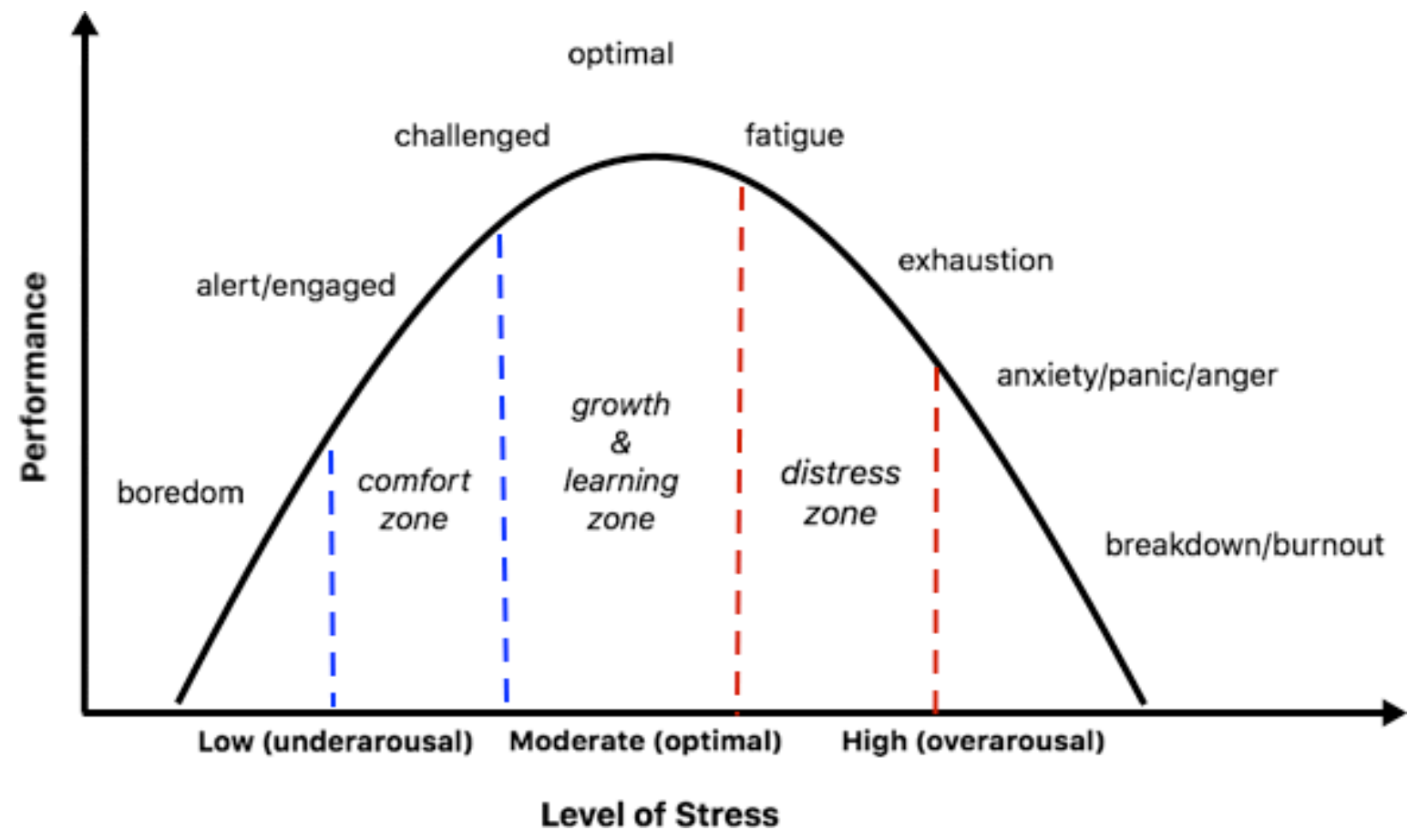

Figure 2: Yerkes-Dodson Law

Source: Yerkes-Dodson Law: Inverted U-relationship between stress/arousal level and performance (see Teigen, 1994). ${ }^{3}$

Stress is needed to achieve optimal stimulation; this is called eustress. This type of stress has a beneficial effect on the body and performance, directing the person into a zone. However, if this exceeds the optimal level, this stimulus will harm the process. This is called distress, which already has detrimental effects on the human body.

"It's not stress that kills you; it's how you react to it." (János Selye)

As I mentioned, inadequately managed stress can be the cause of many illnesses. And efficiency depends on how we adapt to the stressor. In addition to cognitive abilities, the nervous and hormonal systems play a significant role. Stress is followed by the sympathetic effects of the autonomic nervous system. This causes the pupil to dilate, the mouth to dry out, the ECG HR to increase, blood sugar levels to rise, blood to flow from the periphery to vital organs. However, the enteric nervous system (ENS), responsible for two-way communication on the gut-brain axis, should also not be forgotten. ENS is also referred to as the second brain. It affects all functions related to the intestinal tract, including its movement, digestion, excretion, and absorption (CRYAN - O'MAHONY, 2011). There is a lot of research on this as well as problems with the topic. It has also been reported that the altered intestinal-brain axis is related to the background of diseases of gastrointestinal (GI) functions (e.g., reflux, IBS) (DROSSMAN, 2016) (PALMA, COLLINS, \&

https://oxfordre.com/publichealth/oxford/fullsizeimage?imageUri=/10.1093/acrefore/9780190632366.001.00 01/acrefore-9780190632366-e-162-graphic-002-

full.gif\&uriChapter=/10.1093/acrefore/9780190632366.001.0001/acrefore-9780190632366-e-162 
BERCIK, 2014). Several measuring devices can monitor the physiological changes applied to a stressor in the body.

According to Sterbenz et al. (2019), all measurable elements of sports contribute to the final performance that can be statistically analyzed.

Rátgéber et al. (2019) emphasize that psychological factors during sport, such as stress, are also of paramount importance for general health.

A novel and auspicious method are EGG Electrogastography, which monitors GI tract changes in a non-invasive way in real-time, which is related to a person's stress management (FUKUNAGA et al., 2000) (VIANNA - TRANEL, 2006) (VIANNA et al. 2006). Several preclinical trials have served as a sufficient basis to carry out human tests (SZÚCS et al., 2018).

The role of the hormonal system during stress adaptation has been mentioned above. Our body produces three major stress hormones when exposed to stressors. The hormone in the adrenal cortex is cortisol. Adrenaline and noradrenaline, secreted in the adrenal medulla, are the other two hormones that play a significant role in stressful situations. They are responsible for immediate reaction and maintaining alertness. Selye expected the same effect from all kinds of stress. However, we have discussed above that this topic is multifaceted. Franklenhaeuser described a more complex function in which cortisol levels' movement depends on the type of stressor (eustress, distress) that depends on the person's adaptation. He described that stressors that adapt as eustress in a person cause a decrease in cortisol levels because they are in the optimal stage (FRANKLENHAEUSER, 1986).

\section{OBJECTIVE}

Based on our preliminary research and literature reviews, we would like to test and participate in validating a new method that can monitor the effects of stress on humans in real-time, in a non-invasive way, with quantitative results. In addition to GI monitoring, cortisol levels are measured invasively in the subjects, so we hope to obtain complex results.

Our research questions and hypotheses are as follows (see Table 1). 
Vol 4, No 1 (2021): Stadium - Hungarian Journal of Sport Sciences

https://doi.org/10.36439/shjs/2021/1/9450

Table 1: Our research questions and hypotheses

\begin{tabular}{|c|c|}
\hline [Q1] & (H1) \\
$\begin{array}{c}\text { Does the EGIG system show changes in } \\
\text { myoelectric waves in GI organs under } \\
\text { stress? }\end{array}$ & $\begin{array}{c}\text { We hypothesize that the EGIG system will } \\
\text { show myoelectric waves in GI organs that } \\
\text { will rise under stress. }\end{array}$ \\
\hline [Q2] & (H2) \\
$\begin{array}{c}\text { Can any changes in myoelectric waves of } \\
\text { GI organs be observed during latency after } \\
\text { stress? }\end{array}$ & $\begin{array}{c}\text { We hypothesized that during latency, the } \\
\text { myoelectric waves of GI organs would } \\
\text { decrease. }\end{array}$ \\
\hline $\begin{array}{c}\text { What is the relationship between } \\
\text { myoelectric waves of GI organs and } \\
\text { cortisol levels in a stressful situation? }\end{array}$ & $\begin{array}{c}\text { We hypothesized that cortisol levels } \\
\text { would move in parallel with myoelectric } \\
\text { waves in GI organs. }\end{array}$ \\
\hline
\end{tabular}

\section{MATERIALS AND METHODS}

$\mathrm{N}=13$ young athletes participated in the measurement by random selection. The number of men was 11, that of women 2 (women had a stipulation that they could not menstruate). Their average age is $22+/-1,031$ years. Subjects had a pre-stipulation that they were no longer allowed to eat for 3 hours before the measurement. Smoking, coffee, energy drinks, and other caffeinated foods were prohibited on that day.

Our measurements were performed in the Complex Sportbehavior Analysis Laboratory of the Institute of Sport Sciences, University of Debrecen. Our methods were as follows:

We used the Hungarian patented MDE Heidelberg EGIG test method, which monitors the intestinal changes and the gastric myoelectric waves. Thus, a different tract of the intestinal tract can be examined simultaneously, in parallel. "The movement of the stomach and intestines is a function of smooth muscle contraction, and this is generated by myoelectrical changes generated within the system. Therefore, it is also possible to monitor the functioning of the GI system by registering myoelectrical signals, as these are primarily products of the intrinsic neural network and thus represent internal regulation." (FEKETE, 2014). "The EGIG test method with its two sensors and electrodes placed on the abdominal wall is suitable for monitoring bio-electrical changes in the stomach and small and large intestine. Furthermore, the two sensors are capable of simultaneously measuring heart rate variability (HRv), cardiac, circulatory system (ECG), body temperature (TH), and skin galvanic resistance (GSR) on the same monitor in realtime. In this way, it uniquely measures all accepted physiological parameters that underlie stress and do not characterize the stress situation solely based on the other (e.g., heart 
rate). When analyzing the data, it is possible to use different intestinal sections, such as. It is also possible to show correlations with changes in the movement of the small and large intestines, which was not possible with the examination devices so far. Thus, it is also possible that the differences between the individual stress factors can be detected by measuring the right number of elements and performing several different activities and stimuli." (BALOGH, 2016). The accepted method of objective evaluation of waves is Fast Fourier Transformation (FFT) spectrum analysis. The frequency of electrical activity was characterized by cycles per minute (CPM), while its magnitude was characterized by Power Spectrum (PS). The PS values were converted to the fold change (FC) method so that it is easy to examine how the values change compared to the initial resting value.

Cortisol levels were determined from blood and performed in the Clinical Immunology Research Laboratory (the University of Debrecen, Faculty of General Medicine, Institute of Internal Medicine, Department of Clinical Immunology) by ELISA. A qualified nurse took blood samples.

Data were evaluated using Microsoft Excel.

As a stressor, we used the DT package of the VTS program, which is included in the research as an accepted stressor (PATÓCS et al., 2016).

The protocol was as follows:

- 40 minutes resting period

-1st blood collection

- stress period VTS / DT package (approx. 10 minutes)

- 2nd blood collection

- 30 minutes resting period (latency stage 1)

- 3rd blood collection

- 30 minutes rest time (latency stage 2)

- 4th blood collection

The needle was inserted, and the electrodes were placed before the start of the protocol. The EGIG protocol was initiated by continuous recording and proceeded according to the given schedule. The measurement process lasted for a total of $\sim 115$ minutes. It was not allowed to speak during the whole measurement to avoid any interference. 
Vol 4, No 1 (2021): Stadium - Hungarian Journal of Sport Sciences

https://doi.org/10.36439/shjs/2021/1/9450

\section{RESULTS}

Our results are presented in Figures 3 to 7.

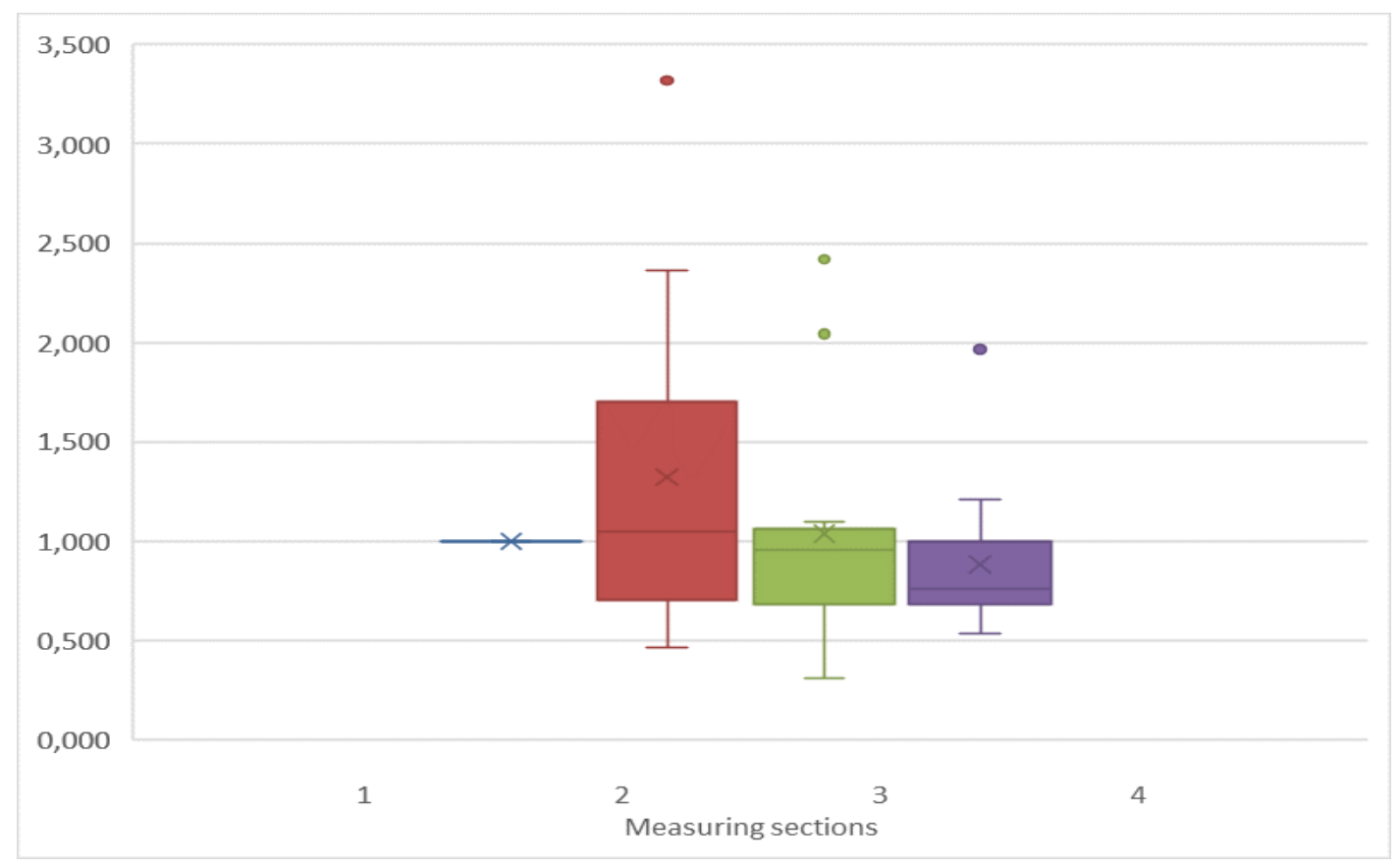

Figure 3: Change in STOMACH PS values in FC

Figure 3 shows the change in gastric PS values. Although with considerable variance during the stress phase, the mean gastric PS FC value rises markedly, increasing from 1 to 1,324. After that, a gradual decrease can be observed over time in the two latency periods: in numbers 1.038 and then 0.883 .

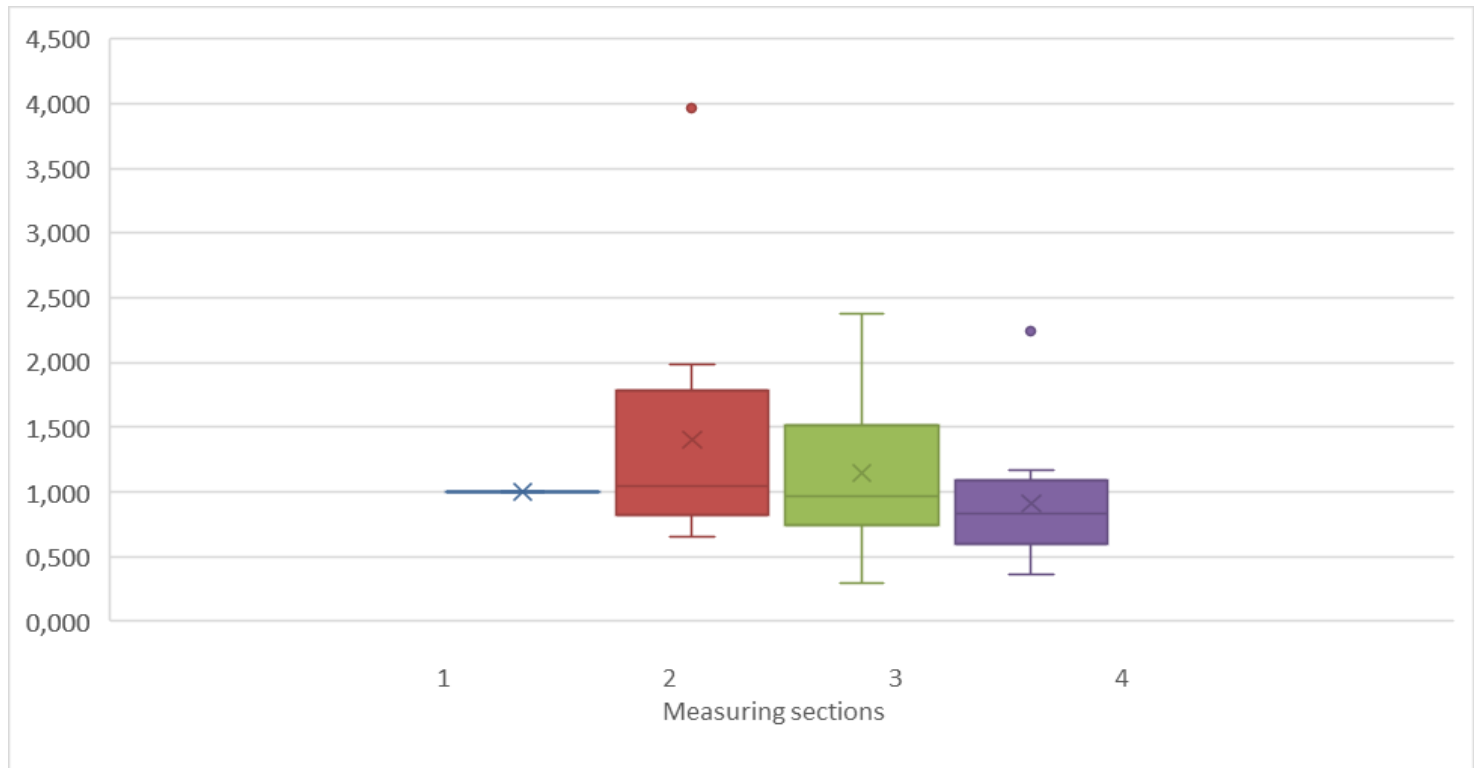

Figure 4: Change in SMALL INTESTINE PS values in FC 
Vol 4, No 1 (2021): Stadium - Hungarian Journal of Sport Sciences https://doi.org/10.36439/shjs/2021/1/9450

Figure 4 shows the change in small intestinal PS values over the four measurement phases. Here, too, it appears that the PS value of the small intestine increases under stress and then gradually decreases during latency. At rest values, rest time: 1 , stress: 1.402, latency 1: 1.146, latency 2: 0.911.

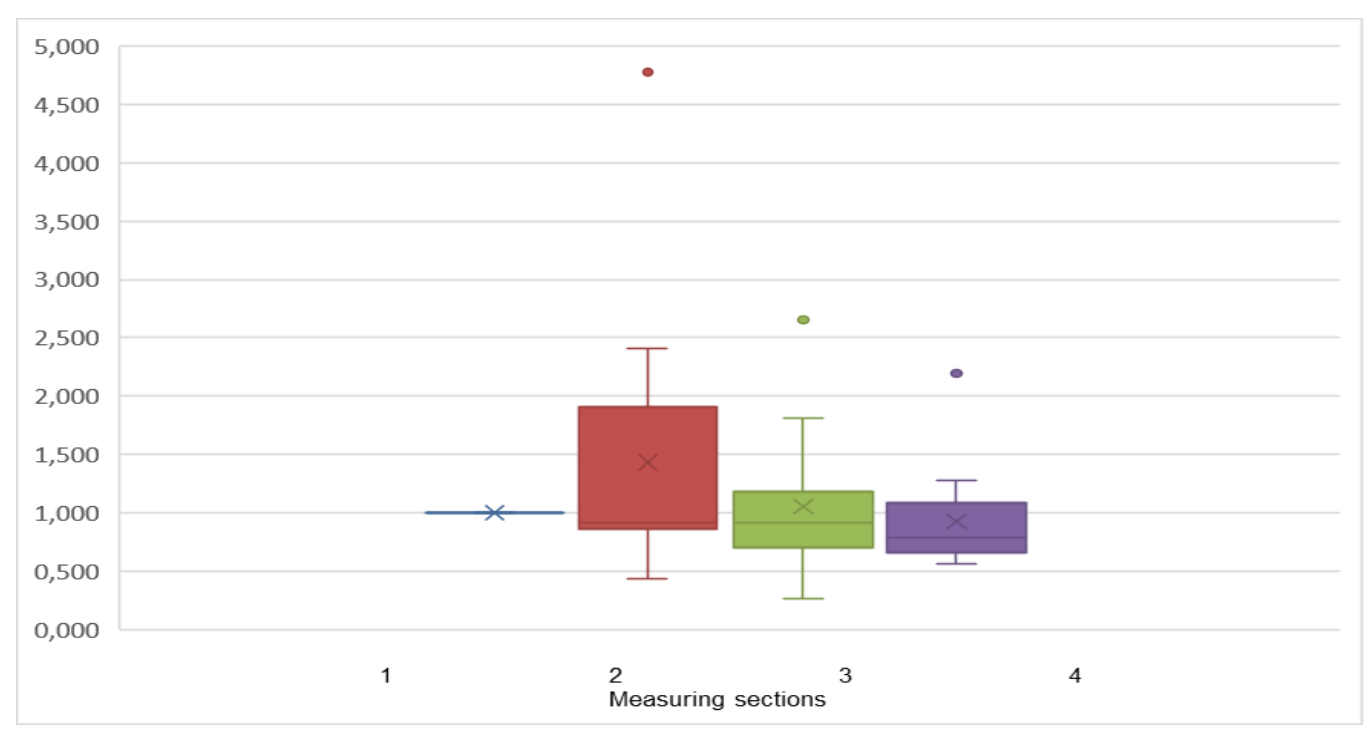

Figure 5: Change of COLON PS values in FC

Colon movement (Fig. 5) also shows a similar PS FC value change in the stress and latency stages. Average values at rest: 1, stress: 1,429, latency 1: 1.052, latency 2: 0.924.

Comparing the previous three results, we can see that the values of the gastric parameters move nicely together, so under stress, the PS FC value of the examined organ increases, and in the latency and resting phase, these values gradually decrease. The following statement is also illustrated in the following figure (see Figure 6).

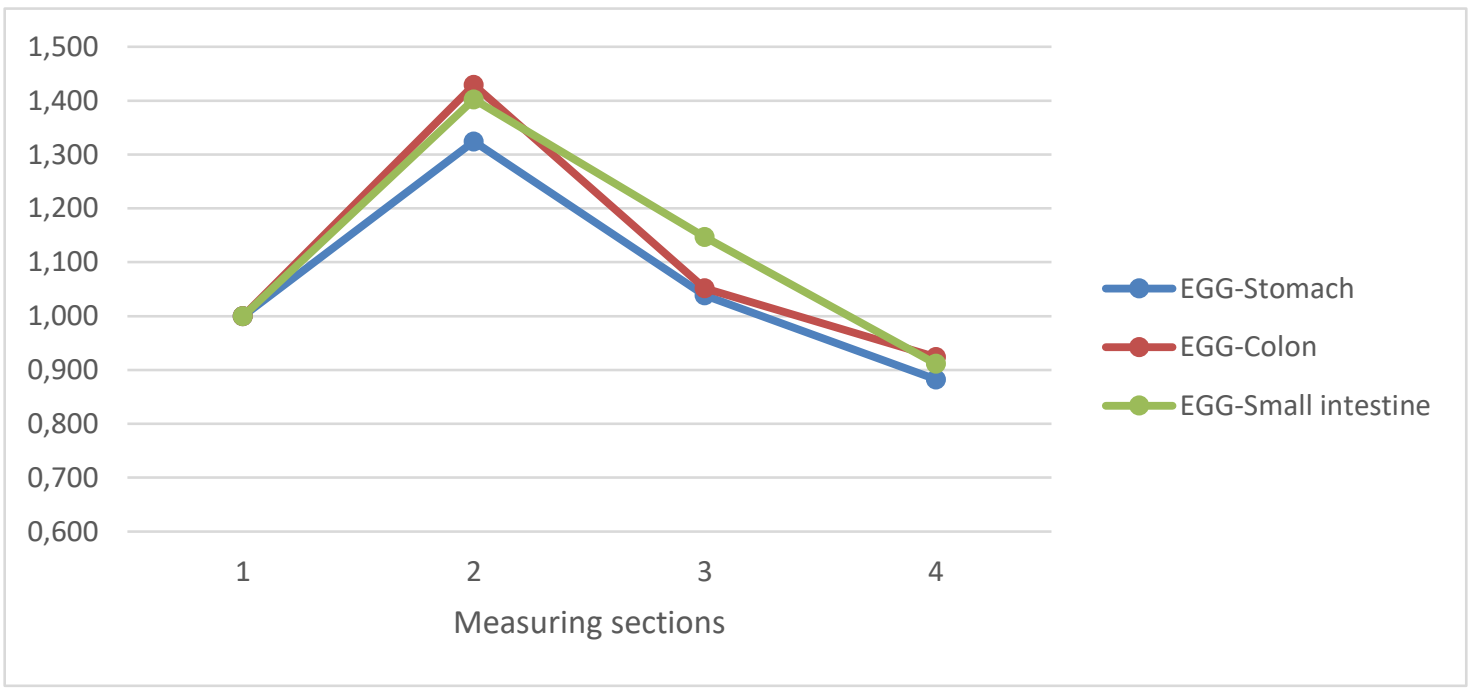


Figure 6: Change of EGG PS values in FC

The change in cortisol levels is no longer as clear (Figure 7). In three participants $(4,5$, 13), the Selye reaction was observed, according to which the value of cortisol increases under stress. Based on the literature mentioned in the introduction, we conclude that the stressor adapted to them as distress.

On the other hand, in the other subjects (except 11), cortisol levels decreased steadily, and even the VTS DT package as a stressor did not increase the value. We conclude that this was a stressor in an optimal zone for the nine subjects adapted as eustress.

However, it is thought-provoking that the needle puncture before the measurement was not this too high stressor. In this case, however, the protocol needs to be refined and changed.

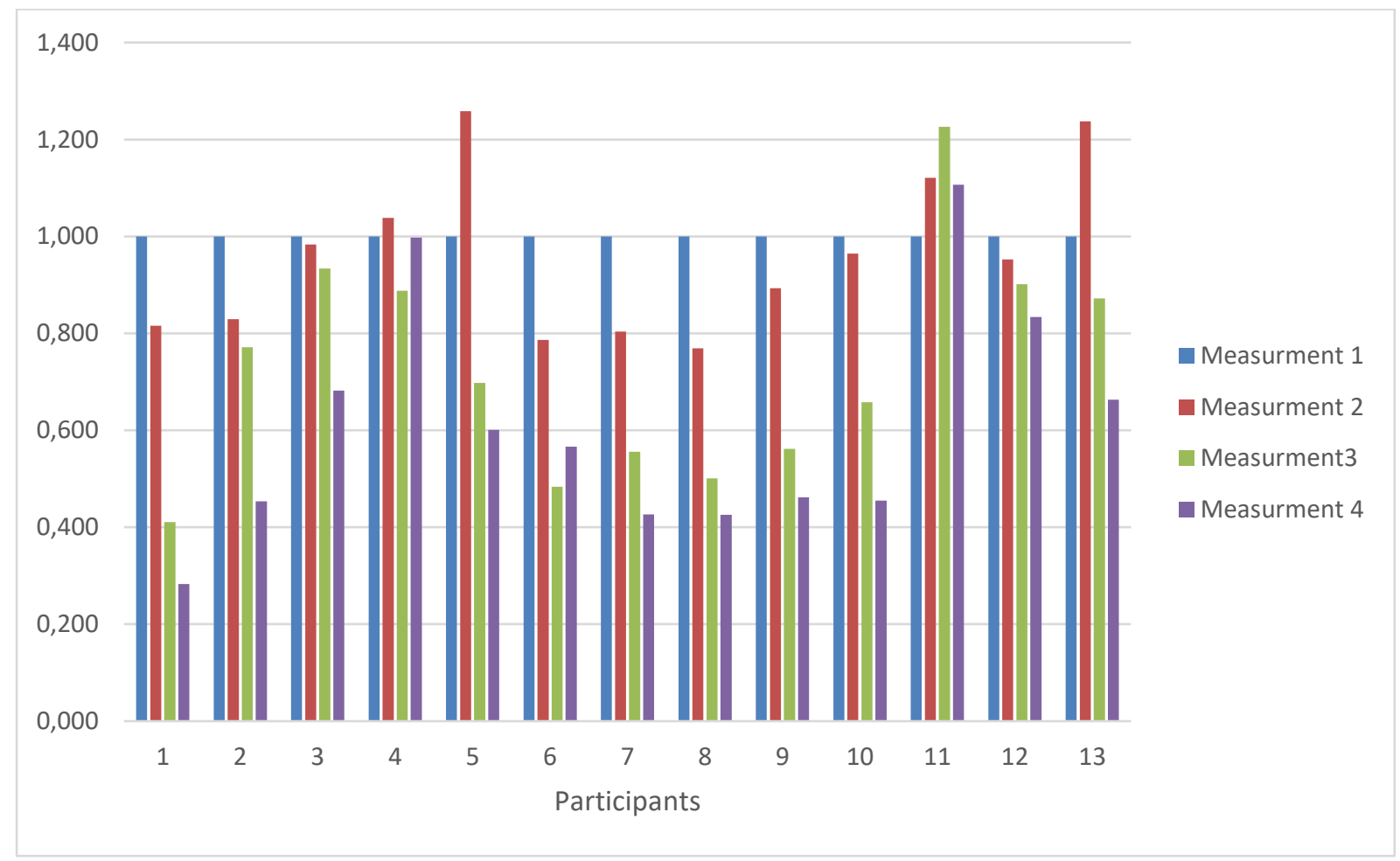

Figure 7: Change in cortisol level values in FC

The above results formulated our hypotheses as follows.

(H1) We hypothesized that the EGIG system would show myoelectric waves in GI organs that will rise under stress.

This has been confirmed, as we have seen. 
Vol 4, No 1 (2021): Stadium - Hungarian Journal of Sport Sciences

https://doi.org/10.36439/shjs/2021/1/9450

(H2) We hypothesized that during latency, the myoelectric waves of GI organs would decrease.

There was a linear decrease in all GI organs during latency times, so our hypothesis was confirmed.

(H3) We hypothesized that cortisol levels would move in parallel with myoelectric waves in GI organs.

We could see that this only happened to a few people, so this hypothesis of ours came into contradiction.

\section{DISCUSSION}

Despite the small number of items, encouraging and valuable results have been obtained, but this is not enough to run the statistical programs or calculate significance. Unfortunately, the coronavirus also impacted our research, but we are glad we could move forward anyway.

Innovative measurement and evaluation methods are highly usable, as they can provide us with many measurement data in a valid, real-time, non-invasive way with a parallel display. These data and results will be used in athlete selection, mental training, elite sports, neuro-biofeedback, and health preservation.

Our goal for the future is to obtain significant values with a higher number of elements and expand the measured parameters and the number of measurement methods. We can get more complex results with these.

The research was supported by: EFOP-3.6.1-16-2016-00022 Debrecen Venture Catapult Programme. 
Vol 4, No 1 (2021): Stadium - Hungarian Journal of Sport Sciences

https://doi.org/10.36439/shjs/2021/1/9450

\section{REFERENCES}

Balogh L., Petrovszki Z., Mikulán R., Nagy, A., Dorka P., \& Molnár A. (2016). Akut pszichés stressz mérésére alkalmas, a gasztrointesztinális rendszer motilitásán alapuló diagnosztikai eszköz tesztelésének eredményei. In: Molnár, Andor; Balogh, László; Viorel, A. P., Alattyányi, István; Győri, Ferenc (szerk.) SPORTTUDOMÁNYI KALEIDOSZKÓP : Sportszakmai tanulmány-, és szakcikk gyűjtemény Szeged, Magyarország : Szegedi Tudományegyetem Juhász Gyula Pedagógusképző Kar, (2016) pp. 70-86. , 16 p.

Balogh L. (2014). To Be in the Zone - Stress and Sport Performance. In: Baczkó, I. et al. (szerk.): European Section Meeting of the International Academy of Cardiovascular Sciences. Programme and Abstract Book. IASC, Balatongyörök, 12-14.

Balogh L., \& Domokos E. (2013). Searching for the Perfect Experience: Through the Comparative Examination of the HipHop Dance and Handball. In: Tsolakidis, E. et al. (szerk): 18th annual Congress of the European College of Sport Science: Book of Abstracts. ECSS, Barcelona, 265-266.

Balogh L. et al. (2015). To be in the Zone - Measurement of stress level with EGIG through elite MX athletes. In: Radmann, A. et al. (szerk): 20th Annual Congress of the European College of Sport Science: Book of Abstracts. ECSS, Malmö, 60

Balogh L., Makra G., Donka D., Pucsok J. M., Bacsne Baba E., Kiss B., Csiki Z., Nagy A., \& Papp G. (2019). Comparative analysis of the effects of regular exercise on immunoregulatory and cognitive abilities in young and elderly adults (abstract).

Balogh L., Meszlényi-Lenhart E., Kecskemétiné PA., Dorka P., Kiss G., \& Győri F. (2015). Sporttudományi fogalomtár.

Cannon W. B. (1926). Physiological Regulation of Normal States: Some Tentative Postulates Concerning Biological Homeostatics. Paris: Editions Medicales. 
Vol 4, No 1 (2021): Stadium - Hungarian Journal of Sport Sciences

https://doi.org/10.36439/shjs/2021/1/9450

Donka D., \& Balogh L., (2018). Fizikai Aktivitás És Stressz A Stresszmérés Metodológiai Problémáinak Vizsgálata - Review. Válogatott Tanulmányok A Sporttudomány Köréből, 1. Kötet, Fókuszban Az Egészség

Fekete L. (2014). Electro-gastro-intestinográfia (EGIG): egy új nem-invazív eljárás a hasi funkciók monitorizálására. [PhD doktori értekezés]. Nemzeti Közszolgálati Egyetem, Budapest

Frankenhaeuser M. (1986). A psychobiological framework for research on human stress and coping. The Plenum Series On Stress And Coping, 101-116.

Fukunaga M., Arita S., Ishino S., \& Nakai Y. (2000). Quantitative Analysis of Gastric Electric Stress Response with Chaos Theory. Biomedical Soft Computing and Human Sciences. 5: 59-64

Kiss B., \& Balogh L. (2019). A study of key cognitive skills in handball using the Vienna test system, Journal of Physical Education and Sport, 19 (1), 733-741

Makra G., \& Balogh L., (2018). Examination of the Relationship Between Physical Activity and Cognitive Skills, Stadium - Hungarian Journal of Sport Sciences, 1 (1).

Nagy A., Almási D., \& Balogh L. (2016). Effects of acute psychological stress measurement in sports - EGIG, an innovative method to state stress response objectively, Arena-Journal of Physical Activities, 8, 110-115.

Nagy T., Kovács K., Polyás Á., Harmat L., Bárdos Gy., \& Fülöp M., (2012). Élvezetes videojáték verseny csökkentette a kortizol szintjét fiatal felnőtt férfiak esetében. Kálmán Erika Doktori Konferencia

Patócs Á., Melia L., Kovács S., Fózer-Selmeci B., Révész L., \& Tóth L. (2016). Reactive stress tolerance and personality characteristics of Hungarian elite fencers. Cognition, Brain, Behavior, 20 (3), 171-184.

Rátgéber L., Betlehem J., Calleja-Gonzalez J., \& Ostojic, S. M. (2019). Basketball for Health: Should We Hop and Shoot for a Remedy? Mayo Clinic Proceedings 94 (2), 364-365. 
Vol 4, No 1 (2021): Stadium - Hungarian Journal of Sport Sciences

https://doi.org/10.36439/shjs/2021/1/9450

Rétsági E., H. Ekler J., Nádori L., Woth P., Gáspás M., Gáldi G., \& Szegnerné D. H. (2011). Sportelméleti ismeretek.

Selye H. (1970).THE STRESS OF LIFE, Columbus: McGraw-Hill.

Selye H. (1975). Confusion and controversy in the stress field, Journal Of Human Stress, 1(2): $37-44$.

Selye J. (1976). Stressz distressz nélkül. Akadémiai Kiadó, Budapest

Selye J. (1978). Életünk és a stressz. Akadémiai Kiadó, Budapest

Sterbenz T., Vilagi K., \& Csurilla G. (2019). Sport Analytics as a tool for an effective decision making. In: Dancs, Henriette; Franks, Ian M.; Hughes, Mike (ed.) Essentials of Performance Analysis in Sport, New York (NY), US : Routledge Paper: chapter 12 , 12 p

Szűcs G., Grosz M., Süle A., Sztojkov-Ivanov E., Ducza A., Márki A., Kothencz L., \& Balogh R. G. (2018). Detection of stress and the effects of central nervous system depressants by gastrointestinal smooth muscle electromyography in wakeful rats Vianna E. P. M., \& Tranel D. (2006). Gastric myoelectrical activity as an index of emotional arousal, International Journal of Psychophysiology, 61, 70-76

Vianna E. P. M., Weinstock J., Elliott D., Summers R., \& Tranel, D. (2006). Increased feelings with increased body signals, Soc Cogn Affect Neuroscience, 1, 37-48. 
Vol 4, No 1 (2021): Stadium - Hungarian Journal of Sport Sciences

https://doi.org/10.36439/shjs/2021/1/9450

\section{Appendix}

Table 1: Measurement results PS, FC

source: own table

\begin{tabular}{|c|c|c|c|c|c|c|c|c|c|c|}
\hline & Cortisol & EGG-Stomach & EGG-Colon & EGG-Small intestine & EKG HR & Cortisol & EGG-Stomach & EGG-Colon & EGG-Small intestine & EKG HR \\
\hline Participan & Measurment 1 & \multicolumn{4}{|c|}{\begin{tabular}{|c|} 
Resting period \\
\end{tabular}} & Measurment 2 & \multicolumn{4}{|c|}{ Stress period } \\
\hline 1 & 1,000 & 1,000 & 1,000 & 1,000 & 1,000 & 0,816 & 1,643 & 1,774 & 1,767 & 0,970 \\
\hline 2 & 1,000 & 1,000 & 1,000 & 1,000 & 1,000 & 0,830 & 0,835 & 0,882 & 1,024 & 1,105 \\
\hline 3 & 1,000 & 1,000 & 1,000 & 1,000 & 1,000 & 0,983 & 1,437 & 1,285 & 1,239 & 1,042 \\
\hline 4 & 1,000 & 1,000 & 1,000 & 1,000 & 1,000 & 1,038 & 0,725 & 0,896 & 0,978 & 0,846 \\
\hline 5 & 1,000 & 1,000 & 1,000 & 1,000 & 1,000 & 1,258 & 1,762 & 2,045 & 3,966 & 0,964 \\
\hline 6 & 1,000 & 1,000 & 1,000 & 1,000 & 1,000 & 0,787 & 1,463 & 0,923 & 1,398 & 1,028 \\
\hline 7 & 1,000 & 1,000 & 1,000 & 1,000 & 1,000 & 0,804 & 1,052 & 0,917 & 0,728 & 1,120 \\
\hline 8 & 1,000 & 1,000 & 1,000 & 1,000 & 1,000 & 0,769 & 0,678 & 0,841 & 1,051 & 1,088 \\
\hline 9 & 1,000 & 1,000 & 1,000 & 1,000 & 1,000 & 0,893 & 3,321 & 4,778 & 1,792 & 1,123 \\
\hline 10 & 1,000 & 1,000 & 1,000 & 1,000 & 1,000 & 0,965 & 0,466 & 0,431 & 0,657 & 1,209 \\
\hline 11 & 1,000 & 1,000 & 1,000 & 1,000 & 1,000 & 1,121 & 0,586 & 0,499 & 0,808 & 1,077 \\
\hline 12 & 1,000 & 1,000 & 1,000 & 1,000 & 1,000 & 0,953 & 2,364 & 2,413 & 1,988 & 1,039 \\
\hline 13 & 1,000 & 1,000 & 1,000 & 1,000 & 1,000 & 1,237 & 0,884 & 0,893 & 0,833 & 1,088 \\
\hline & Cortisol & EGG-Stomach & EGG-Colon & EGG-Small intestine & EKG HR & Cortisol & EGG-Stomach & EGG-Colon & EGG-Small intestine & EKG HR \\
\hline Participan & Measurment3 & \multicolumn{4}{|c|}{\begin{tabular}{|l|} 
Latency stage 1 \\
\end{tabular}} & Measurment 4 & \multicolumn{4}{|c|}{\begin{tabular}{|l|l|} 
Latency stage 2 \\
\end{tabular}} \\
\hline 1 & 0,411 & 0,698 & 0,925 & 0,756 & 0,901 & 0,283 & 0,539 & 0,676 & 0,360 & 0,931 \\
\hline 2 & 0,771 & 0,710 & 0,717 & 1,055 & 0,916 & 0,454 & 0,757 & 0,697 & 0,999 & 0,970 \\
\hline 3 & 0,934 & 1,096 & 1,323 & 1,744 & 0,959 & 0,682 & 0,717 & 0,726 & 1,163 & 0,986 \\
\hline 4 & 0,888 & 1,031 & 1,035 & 1,165 & 1,045 & 0,997 & 0,563 & 0,563 & 0,692 & 0,996 \\
\hline 5 & 0,698 & 2,043 & 1,808 & 2,382 & 0,960 & 0,601 & 1,967 & 2,193 & 2,240 & 0,918 \\
\hline 6 & 0,484 & 0,996 & 0,858 & 0,743 & 0,965 & 0,567 & 0,836 & 0,646 & 0,570 & 0,893 \\
\hline 7 & 0,556 & 0,957 & 0,978 & 0,904 & 0,999 & 0,427 & 0,685 & 0,788 & 0,631 & 0,949 \\
\hline 8 & 0,501 & 0,674 & 0,685 & 0,706 & 1,010 & 0,426 & 0,745 & 0,817 & 0,878 & 0,991 \\
\hline 9 & 0,562 & 2,421 & 2,655 & 2,154 & 0,958 & 0,462 & 1,087 & 1,281 & 1,011 & 0,970 \\
\hline 10 & 0,658 & 0,307 & 0,259 & 0,301 & 0,710 & 0,455 & 0,677 & 0,639 & 0,526 & 0,978 \\
\hline 11 & 1,226 & 0,974 & 0,913 & 0,968 & 0,978 & 1,106 & 1,208 & 1,023 & 1,174 & 1,002 \\
\hline 12 & 0,901 & 0,927 & 0,852 & 1,288 & 1,028 & 0,834 & 0,774 & 0,818 & 0,834 & 1,031 \\
\hline 13 & 0,872 & 0,664 & 0,668 & 0,739 & 0,981 & 0,663 & 0,916 & 1,143 & 0,770 & 0,984 \\
\hline
\end{tabular}

